\title{
Improving Food Systems: A Participatory Consultation Exercise to Determine Priority Research and Action Areas in Viet Nam
}

\author{
Trang Nguyen ${ }^{1 *}$, Marrit van den Berg ${ }^{1}$, Jessica E. Raneri ${ }^{2,3,4}$ and Tuyen Huynh ${ }^{5}$ \\ ${ }^{1}$ Development Economics Group, Wageningen University and Research, Wageningen, Netherlands, ${ }^{2}$ Senior Nutrition \\ Sensitive Agriculture Advisor, Australian Centre for International Agricultural Research, Canberra, ACT, Australia, ${ }^{3}$ Senior \\ Nutrition Sensitive Agriculture Advisor, Agricultural Development and Food Security Section, Department of Foreign Affairs \\ and Trade, Canberra, ACT, Australia, ${ }^{4}$ Department of Food Technology, Safety and Health, Faculty of Bioscience \\ Engineering, Ghent, Belgium, ${ }^{5}$ Food Environment and Consumer Behavior Lever, International Center for Tropical Agriculture \\ (CIAT)-Asia Office, Hanoi, Vietnam
}

With increased burden of malnutrition on global health, there is a need to set clear and transparent priorities for action in food systems at a global and local level. While priority settings methods are available for several adjacent domains, such as nutrition and health policies, setting priorities for food system research has not been documented and streamlined. The challenges involve food systems' multisector, multi-stakeholder and multi-outcome nature. Where data exists, it is not easy to aggregate data from across food system dimensions and stakeholders to make an informed analysis of the overall picture of the food system, as well as current and potential food system trade-offs to inform research and policy. Once research priorities are set, they risk staying on paper and never make their ways to concrete outputs and outcomes. In this paper, we documented and assessed the inclusive process of setting research priorities for a local food system, taking Vietnamese food systems as a case study. From this exercise, we examined how priority setting for food systems research could learn from and improve upon earlier priority setting research practices in other domains. We discussed the lessons for research and policies in local food systems, such as the need for a concrete follow-up plan accompanying the priority setting process.

Keywords: food systems, research priority setting, interdisciplinary research, Viet Nam, healthier diets

\section{INTRODUCTION}

Achieving a world with no poverty, zero hunger, reduced inequalities, and responsible production and consumption are all key challenges of the Sustainable Development Goals (United Nations, 2015). A food systems' perspective provides an encompassing approach to consider all of these issues. While global priorities for food systems research are available (Haddad et al., 2016; HLPE, 2017), local research priority setting is necessary to navigate the research agenda toward sustainable outcomes. Setting research priorities is a formal procedure to generate consensus between different stakeholders on research questions considered a priority for resources allocation (Viergever et al., 2010). Researchers, policy-makers and other stakeholders can effectively target research that has the greatest potential benefits, optimizing the allocation of limited resources. A rational and transparent formulation of research priority questions would prove useful for many 
local food systems, especially in low and middle income countries (LMICs) that are most affected by a poorly functioned food system. Nevertheless, paucity of detail about the priority setting process and lack of transparency is common across many LMICs (Tomlinson et al., 2011).

Although priority-setting exercises have been welldocumented in nutrition and health domains (Viergever et al., 2010; Tomlinson et al., 2011; McGregor et al., 2014; Mador et al., 2016; Timotijevic et al., 2019), such a process for food system research has been rare. Recent examples include the works by Gebru et al. (2018), De Brauw et al. (2019), and Raneri et al. (2019). However, these working papers stopped at the list of research questions, without a detailed documentation and reflection of the priority setting process. Food system research requires a unique approach to respond to interconnected challenges and constraints, as food systems encompass multiple sectors and multiple disciplines (Ruben et al., 2018), multiple domains, including not only dietary outcomes, but also health, sustainability and socio-economic outcomes (HLPE, 2017), and involves a large amount of interdisciplinary data (Battersby, 2020). This makes priority setting for food systems research a more involving task than priority setting for a single research domain. As the body of work on food system research has grown exponentially (Béné et al., 2019; Fanzo et al., 2020), an analysis of the priority setting process would be helpful for future endeavors to avoid the research waste, which involves ignoring the needs of potential users of research evidence and overlooking what is already known or already being researched (Chalmers et al., 2014).

To illustrate the process of research prioritization for a local food system, we took Vietnam as a case study. Vietnam is a middle income country that offers a vivid example of local food systems in rapid transformation. During the country's steady economic growth following the economic reforms in 1986, the average caloric intake increased in almost all regions of the country, protein-rich consumption increased, and the prevalence of undernutrition was lowered (Molini, 2006; Le Nguyen et al., 2013). At the same time, Viet Nam has been observing the transition from traditional diets toward unhealthy food consumption patterns such as high consumption of salt, ultra-processed foods (including instant noodles) and sweetened non-alcoholic beverages, as well as lower consumption of fresh fruit, vegetables and seafood (Nguyen and Hoang, 2018). The food system factors behind these diet transformations have been linked to the country's increased prevalence of overweight and obesity (Ha et al., 2011) and an increased burden of disease and prevalence of non-communicable diseases (NCDs), all of which increase pressure on the national health care system (Nguyen and Hoang, 2018). Viet Nam's rapid urbanization rate, which is expected to remain above 3 percent annually, and the country's now globally integrated economy, whose trade volume accounts for 178 percent of its GDP (World Bank, 2017), will continue to be catalysts for the nutrition transition currently underway. These dynamic drivers makes Vietnam an excellent case study for applying the food systems frameworks to identify research priorities in a local food system. The food system research priority setting (FSRP) process in Vietnam, therefore, can offer many relevant discussions to improve the overall approach across different contexts.

This paper describes and reflects on the process of setting priorities for food systems research in Viet Nam. It summarizes the best practices from adjacent domains, such as health and nutrition priority setting, that food systems research priority setting (FSPR) can adopt, and discusses what has to be adjusted or complemented to account for the requirements of food systems research. By assessing the FSRP process in Viet Nam against these considerations, we draw lessons and suggest approaches for future attempts.

Following this introduction, the paper is structured as follows: the next section briefly describes the approaches used in priority setting, how FSRP can learn from them and the additional challenges involved in FSRP. It ends with a sketch of a proposed approach for FSRP. The next section describes the process of FSRP in Vietnam, which is followed by a discussion of the process. The final section concludes and gives some policy implications.

\section{PRIORITY SETTING FOR FOOD SYSTEMS RESEARCH}

While there is no gold standard for priority setting, good practices have been documented, most dominantly in health research (Montorzi et al., 2010; Viergever et al., 2010). In this section, we give a brief overview of the approaches used in priority setting, discuss their relevance for FSRP and the challenges of FSRP.

\section{Good Practices in Health and Nutrition Research Priority Setting}

Health research prioritization has a similar goal with that of FSRP. It aims to maximize impact of investments, especially in resource-poor environments, to strengthen health research system and respond to community health needs (Viergever et al., 2010; McGregor et al., 2014). Setting priorities in health research plays an essential role in responding to increased disease burdens and progressing development goals (Chongtrakul and Okello, 2000; McGregor et al., 2014). In FSRP at a global level, it has been pointed out that urgent interdisciplinary research is needed to support concerted policy action in crafting and sustaining food systems to provide nutritious diets for all (Haddad et al., 2016). Both health research prioritization and FSRP share the common end-goal of health outcomes to respond to development challenges.

FSRP can adopt several approaches used in health research priority setting. Although there is no standard on research priority setting due to varied contexts, the general census is that the processes should be fair, legitimate, evidence-based, inclusive of a broad spectrum of stakeholders, and transparent (Tong et al., 2019). Reviews of health research priority setting exercises have been conducted in both high income countries and LMIC settings (Bryant et al., 2014; McGregor et al., 2014). In a variety of LMICs, the most common process to elicit priorities was a workshop/ conference without any explicit specification 


\section{Preparatory work}

\section{Context}

Decide which contextual factors underpin the process: What resources are available for the exercise? What is the focus of the exercise (i.e. what is the exercise about and who is it for)? What are the underlying values or principles? What is the health, research and political environment in which the process will take place?

\section{Use of a comprehensive approach}

Decide if use of a comprehensive approach is appropriate, or if development of own methods is the preferred choice. These approaches provide structured, detailed, step-by-step guidance for health research priority setting processes from beginning to end.

\section{Inclusiveness}

Decide who should be involved in setting the health research priorities and why. Is there appropriate representation of expertises and balanced gender and regional participation? Have important health sectors and other constituencies been included?

\section{Information gathering}

Choose what information should be gathered to inform the exercise, such as literature reviews, collection of technical data (e.g. burden of disease or cost-effectiveness data), assessment of broader stakeholder views, reviews or impact analyses of previous priority setting exercises or exercises from other geographical levels.

\begin{tabular}{l} 
5. Planning for implementation \\
Establish plans for translation of the priorities to actual research (via policies and funding) as a priority at the \\
beginning of the process. Who will implement the research priorities? And how? \\
\hline \multicolumn{1}{c}{ Deciding on priorities } \\
\hline 6. Criteria \\
Select relevant criteria to focus discussion around setting priorities \\
7. Methods for deciding on priorities \\
Choose a method for deciding on priorities. Decide whether to use a consensus based approach or a metrics based \\
approach (pooling individual rankings), or a combination.
\end{tabular}

\section{After priorities have been set}

\section{Evaluation}

Define when and how evaluation of the established priorities and the priority setting process will take place. Health research priority setting should not be a one-time exercise!

\section{Transparency}

Write a clear report that discusses the approach used: Who set the priorities? How exactly were the priorities set?

FIGURE 1 | Checklist for health research priority setting (Viergever et al., 2010).

of established research priority setting methods (24\%), followed by the Child Health and Nutrition Research Initiative (CHNRI) method (Rudan, 2016) ${ }^{1}(18 \%)$ and a stepwise process including a literature review, in-depth interviews and consultation (18\%). The application of criteria to determine research priorities was used in $67 \%$ of reports. Viergever et al. (2010) proposed a checklist for health research priority setting and outlines nine common themes of good practice to assist health research prioritization processes before, during and after undertaking priority setting (Figure 1). The process of priority setting can be influenced not only by the stakeholders, but also objective

\footnotetext{
${ }^{1}$ The CHNRI method uses a systematic approach to listing a large number of possible research ideas, using the " $4 \mathrm{D}$ " framework (description, delivery, development and discovery research) and a well-defined "depth" of proposed research ideas (research instruments, avenues, options and questions), welldefined context and criteria, and consensus development through measuring collective optimism among a larger group of experts (Rudan, 2016).
}

factors like budgetary requirements, tradition and local cultures (Bukachi et al., 2014).

Hofmarcher-Holzhacker et al. (2017) makes the distinction between setting priorities for health information research and setting priorities for health intervention or healthcare provision. In selecting an optimal portfolio of health interventions, programs or policies, the traditional economic approach can be utilized by ranking programs according to their costeffectiveness ratio. Other quantitative approaches such as simulation modeling, optimization methods and integrated assessment modeling have been used in supporting priority setting in agricultural research (Thornton et al., 2018). Difficulties in ranking (prioritizing) include limitations in economic evaluation methodology, incorporating equity principles, and practical constraints (Hauck et al., 2015). Although measuring the ex post impacts of research with quantitative metrics and qualitative narratives is possible, ranking research priorities with economic evaluation is not feasible ex ante, as the pathways from 
research to impact are hard to quantify. Almost $70 \%(2,110)$ of the identified research priorities at the World Health Organization were developed without using any additional criteria, besides literature review and expert consultation, to rank the priorities with respect to potential public health impact, feasibility of undertaking the research or cost (Terry et al., 2018).

In health priority setting, there was limited evidence of any implementation or follow-up strategies after the priority setting process. Initial identified challenges included engagement with stakeholders, data limitations through limited published information available, and limited capacity to implement research priorities (McGregor et al., 2014). As we will explain in the next section, overcoming this challenge would also play an important role in FSRP.

Within health research priority setting, nutrition research priority setting is an area in particular adjacent to food systems, as its topics of outcomes are also among the key outcomes of food systems. A review by Hawwash et al. (2018) mentioned 53 papers in nutrition priority setting, covering a range of topics such as obesity, wasting, stunting, malnutrition. Most papers used a combination of methods, including debates and discussions, Delphi process, and CHNRI. The majority of the papers did not describe follow-up activities of the proposed priorities. Following this finding, and amidst the concern about research waste, Hawwash et al. (2021) assessed how priority setting exercises for research are considered in publication. They found that although half of the priority setting exercises' authors were positive about their priority setting exercise impact, priority setting exercises are rarely cited for the purpose of acting on the proposed research priorities. Key identified barriers for uptake of research priories were challenges in involving stakeholders and the general public for participation in the priority setting exercise (Hawwash et al., 2021). It was proposed that the presence of the funders and guided discussion between funders, researchers, and other stakeholders at the beginning of the priority setting exercises; and knowledge transfer between different priority setting exercises could help to increase uptake of priority setting exercises' recommendations. This proposal is particularly relevant for FSRP, which is a fairly new exercise.

\section{Challenges of Setting Priority for Food System Research}

Despite sharing similarities with health and nutrition research, food systems research has several characters that makes FSRP a more challenging task.

Food systems encompass multiple sectors and multiple disciplines (Figure 2). A food system "gathers all the elements (environment, people, inputs, processes, infrastructures, institutions, etc) and activities that relate to the production, processing, distribution, preparation and consumption of food, and the outputs of these activities, including socio-economic and environmental outcomes" (HLPE, 2017). Food systems analysis asks for support from a wide variety of disciplines and also requires the involvement of multiple stakeholders, including the engagement of other (non-science) parties in the research process (Ruben et al., 2018). In health research, it's possible to

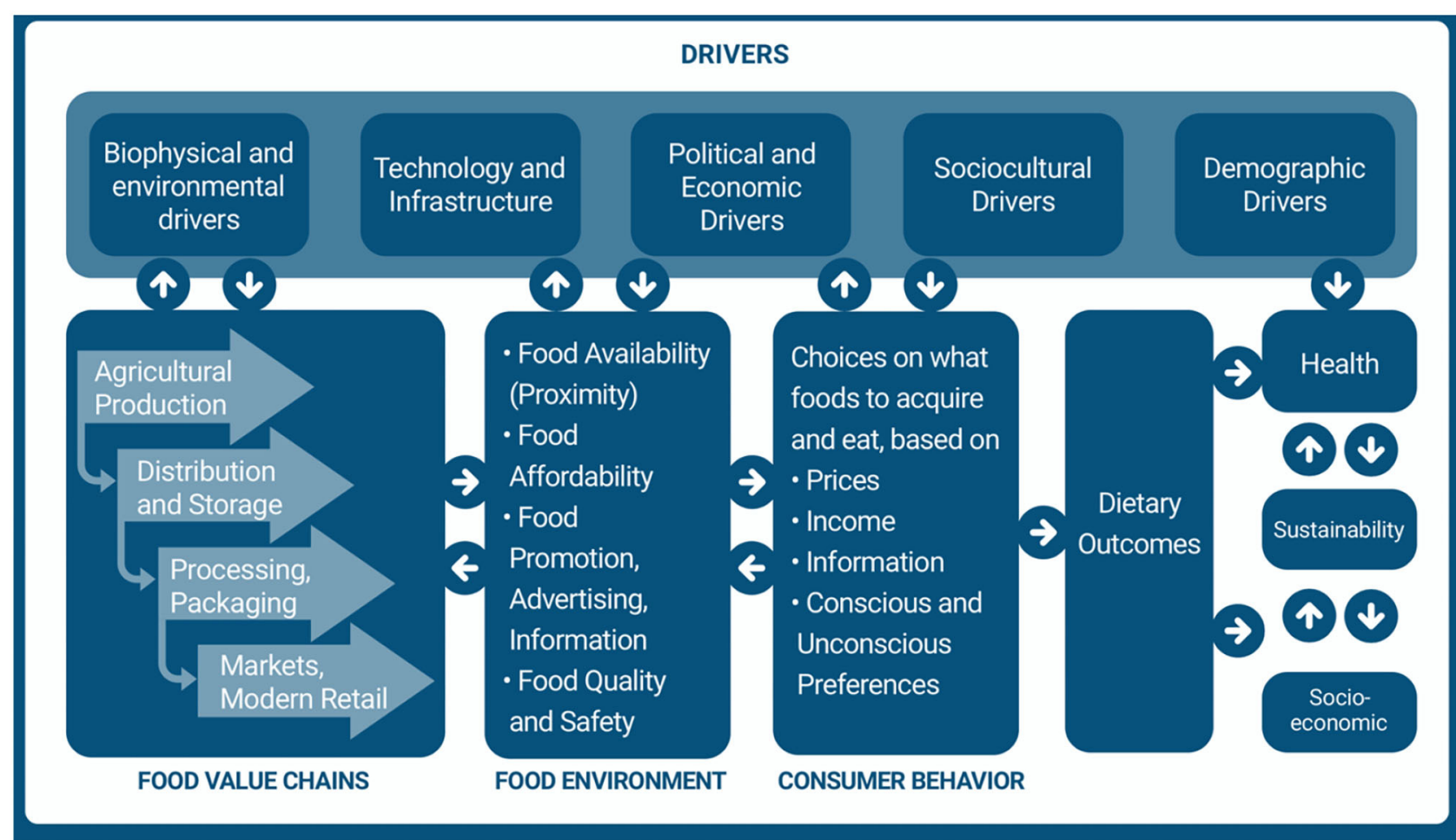

FIGURE 2 | Food systems components. From De Brauw et al. (2019), based on the HLPE framework. 
set priorities for sub-domains such as early child development and violence prevention (Rudan et al., 2010; Tomlinson et al., 2017) and aging (Doolan-Noble et al., 2019). Although breaking down food systems into several domains may be an attractive option, one can lose sight of the synergies and trade-offs that are inherent among the components of the food systems (HLPE, 2017; Béné et al., 2019). It has been argued that trade-offs between different outcomes are key to consider in the transition toward a sustainable food system and should be central to food system research (Béné et al., 2019). Therefore, it is useful to include a discussion of synergies and trade-offs alongside or after characterizing the food system components.

The broad multi-stakeholder cooperation and knowledge exchange is particularly important to take into account the full spectrum of food system research. The myriad parts of the food system can have interactions with each other and the vast amount of work is needed to make even small changes. Nutrition, public health, agriculture, and the food industry need to work together to solve interconnected problems (Finley et al., 2017). As a result, challenges with stakeholder engagement faced by health research priority setting exercises (McGregor et al., 2014; Hauck et al., 2015) will be even more prominent in food system research priority setting. de Koning et al. (2021) suggested different approaches at different level to support stakeholder engagement: an approach that recognizes the value of different types of knowledge and paradigms from different disciplines, a method that is open, inclusive, and reflexive with different steps, and tools that support exploration, positioning and identifying pathways and actions from the perspective of stakeholders.

Food system outcomes cover multiple domains, including not only dietary outcomes, but also health, sustainability and socio-economic outcomes (HLPE, 2017). Assessing the benefits and costs of a food system intervention is therefore complicated, thus making the judgement on the priority level of a research initiative difficult. For example, severity of the outcome of a disease burden, a common criterion used in health research priority setting, would have to be tweaked to account for several outcomes. A healthy diet for consumers should also seek to promote synergies between health and sustainability (Béné et al., 2019). As multiple stakeholders are motivated by different incentives, defining a set of selection criteria among stakeholders to account for different outcomes is puzzling. To illustrate, investments in better waste management (environmental outcome) tend to increase overall market availability that leads to lower producer prices (socio-economic outcome), thus taking away the initial incentive for engagement by producers. This challenge is closely related to the previous one on identifying synergies and trade-offs among components of the food systems. The amount of research on trade-offs is still limited, which constrains the navigation of efficient and equitable choices (Béné et al., 2019).

Due to its large coverage, food systems research involves a large amount of interdisciplinary data. This means that the step of information gathering, as a preparatory step for determining research priorities, demands significant time and coordination. The required data include not only data pooled from different sectors, but also from different time points, due to adaptive processes and dynamic drivers of the food systems. Defining the boundary for literature and data gathering is therefore important. A recent data effort to characterize available food system data from Viet Nam indicated that while there are few primary datasets with repeated use of instruments, access options for the majority of datasets was unclear and dependent on the data producing institution (the authors could access less than half of the raw data), and data on food processing and distribution and food loss and waste were lacking (Burra et al., 2019). Data collection to inform FSRP therefore requires flexible approaches, including secondary data review and consultation with experts and policy makers to approach relevant data producing institutions.

\section{Proposed Approach and Methods for Food Systems Research Priority Setting}

For FSRP, the core criteria for research priority setting are that it should be evidence-based, inclusive of a broad spectrum of stakeholders and transparent. We have not included fairness and legitimacy (Tong et al., 2019) in this list as we believe that these are nested in the other criteria: active participation of sufficient relevant stakeholders and transparent reporting will make the process fair and give it legitimacy. The criteria evidence-based and inclusiveness can be met through an interactive process involving literature review, secondary data analysis and stakeholder consultations (see Figure 3). For transparency, clear and public reporting throughout the process is required.

Compared to research priority setting exercises in nutrition and health, FSRP face additional challenges due to the broadness of the system, which has implications for both the information to be collected and the stakeholders to be invited. A common framework such as Figure 2 will help structure all activities. The information searches and reporting can be structured around the various components of the food system: drivers, food value chains, food environment, consumer behavior, and outcomes. In addition, such a framework can help ensure that a sufficiently broad group of stakeholders gets invited. Ideally, one may want all boxes of the framework covered by participants in the process. In practice, it suffices to invite stakeholders for the domains that have been identified as most relevant for the specific food system under study. Key is to invite both researchers from the relevant disciplines as non-research stakeholders from the relevant sectors and backgrounds.

The framework also incorporated the essential activities (represented by the boxes in Figure 3) suggested by Viergever et al. (2010) at different stages of priority setting. From the checklist, we separated the activities from the criteria (transparency, inclusiveness). The three main research methods (Literature review, secondary data analysis and stakeholder consultation) provide the necessary information to carry out these activities.

\section{Literature Review}

Investment in additional research should always be preceded by an assessment of existing evidence (Chalmers et al., 2014). Literature review and secondary data analysis are essential 


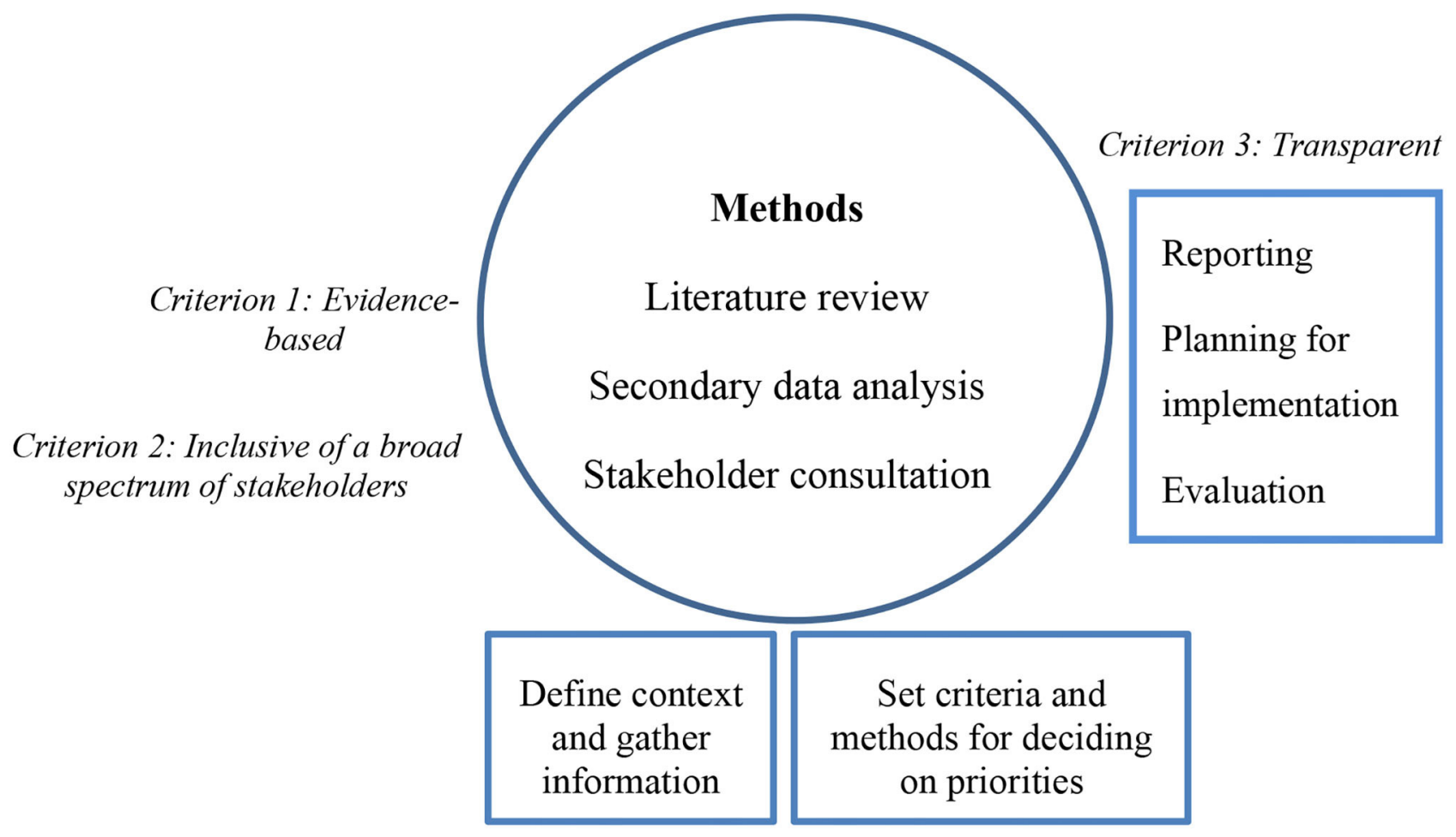

FIGURE 3 | Conceptual framework of FSRP.

to ensure that the process is evidence-based. Information is needed throughout the process and the level of detail will differ depending on the stage of the process. At the start of the process, the core purpose of the information search will be the identification of the key themes relevant for the country or region studied. These can form the basis of the first stakeholders consultations: who gets invited and what is the agenda of the meeting(s). Later in the process, more detailed information about the relevant food system is needed: What is already known and where are knowledge gaps. Earlier stakeholder consultations can help focus the information search on areas most relevant for the specific food system.

\section{Secondary Data Analysis}

Food systems analysis to inform FSRP can benefit from secondary data analysis, especially longitudinal data to capture the trends in food systems changes. Secondary data analysis that pools data from different domains can also help discover the relationships, as either synergies or trade-offs, among different components of the food systems. Despite the local focus, the analysis should include both global and local data to allow comparison, aligning the national priorities with international ones. Data from both international and national sources should be triangulated. As food systems research data can come from different scientific disciplines, it is useful to have an interdisciplinary team to support interpretation.

\section{Participatory Stakeholder Workshops}

Similarly to literature review, participatory stakeholder workshops are best held more than once throughout the process. For example, early in the process, stakeholders can be consulted to brainstorm the research questions according to the key themes identified by the researchers. In a later stage, after further information has been collected and a set of specific research questions has been identified, a second stakeholder consultation workshop can be organized to validate the findings and prioritize the research questions. Priority setting can be done by consensus or by vote. We argue that voting is the appropriate method for the highly diverse group of FSRP participants to avoid dominance of specific groups or people and allow equal participation of all.

\section{RESEARCH PRIORITIZATION PROCESS IN VIET NAM}

Setting research priorities for Viet Nam's local food system was part of the efforts to characterize the food system at the start of a large research program ${ }^{2}$. Instead of limiting

\footnotetext{
${ }^{2}$ The exercise was part of the flagship Program Food Systems for Healthier Diets (FSHD), CGIAR Research Program on Agriculture for Nutrition and Health $(\mathrm{A} 4 \mathrm{NH})$ portfolio. FSHD focuses on food systems through the agri-food value chains impact pathway and the associated policy enabling required to accelerate food system innovation, scaling, and anchoring. A core group of researchers from WUR, Bioversity, CIAT and ILRI were tasked with initiating this activity.
} 
the process to a researcher-led exercise, the researchers took this opportunity to involve national stakeholders in setting research priorities for food systems in Viet Nam. An increasingly diverse group of stakeholders joined toward the end of the priority-setting exercise. The multidisciplinary, multistakeholder approach served the following objectives: first, to align the research activities with the policy interests; second, to sensitize stakeholders with the food system approach; and third, to increase uptake of research results through joint ownership of the research agenda.

Although the process to determine priority research and action areas in Viet Nam did not follow a fully standardized approach, it can be divided in three main stages: preparatory work, determination of research priorities, and follow up (Figure 4). For each stage, we discuss how the process utilized the conceptual framework for FSRP in the previous section. After tracing the activities at each stage in this section, we reflect on how the process followed or deviated from the suggested good practices of research priority setting (Viergever et al., 2010; Mador et al., 2016) in the Discussion.

\section{Preparatory Work}

Literature review and participatory workshops were used from the beginning. To prepare for the first participatory workshop, stakeholder representatives that needed to be involved in the research priority setting exercise were identified and invited to the co-planning workshop in September 2016. In this workshop, besides researchers from within the initiating program $\mathrm{A} 4 \mathrm{NH}$ (CIAT, IFPRI, ILRI, WUR) and outside A4NH with presence in Viet Nam (CASRAD, FAVRI, CIRAD), different sectors and constituencies were involved: civil society (Health Bridge, GAIN), policymakers (National Institute of Nutrition, Ministry of Industry and Trade), funders/donors (FAO), and the private sector (Fresh Studio). The invited stakeholders who would like to contribute in the next stages of the priority setting process were also identified here. In terms of literature review, the researchers carried out a rapid identification of the main themes related to Viet Nam's food systems to facilitate brainstorming and discussion. The researchers' knowledge of known resources on relevant topics to the food system was utilized to identify the key themes. These themes were (i) Healthy Diets, (ii) Value Chains, (iii) Policy, and (iv) System Dimensions. The first two themes

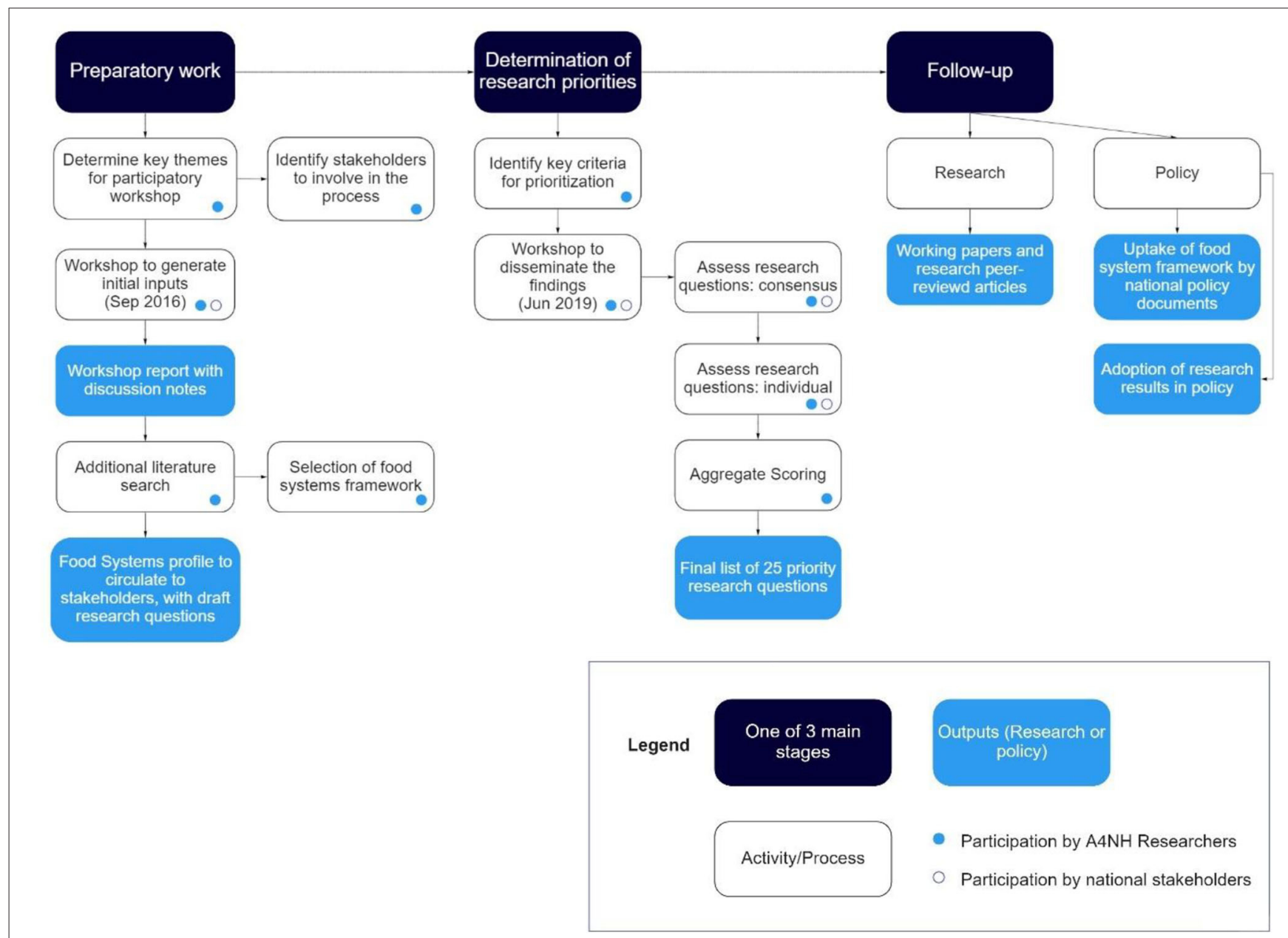

FIGURE 4 | Research priority setting process in Vietnam. 
TABLE 1 | Participants in the first participatory workshop.

\begin{tabular}{lcll}
\hline Domain & & Labor sector \\
\hline Agriculture production/value chains & 14 & Researchers outside CGIAR & 9 \\
Nutrition and healthy diets & 3 & National government & 4 \\
Trade & 1 & Non-government organization & 2 \\
Policies & 2 & Private sector & 3 \\
& & International organization & 1 \\
\hline
\end{tabular}

are integral to any food systems framework. The third theme was selected in particular to examine the potential of aligning the research priorities with policy implementation. The objective of the fourth theme was to grasp how the current systems lens was adopted by stakeholders. The researchers from CGIAR centers led this exercise, with additional participation from other sectors (Table 1).

In the workshop, the participants were randomly divided in four groups corresponding to the four themes. Each group discussed, identified and prioritized key research and development areas to be addressed, taking into account the Vietnamese context and perceived user demands. The findings of these group discussion were summarized in an internal report that represents the first output of the research priority setting process (Supplementary Annex 1). This report was shared with all the participants and within the $\mathrm{A} 4 \mathrm{NH}$ network, ensuring the first part of the process was transparent.

Following the first stakeholder workshop, the second extensive literature review was carried out to characterize the food systems in Viet Nam. The key words and research questions identified by workshop participants worked as initial inputs for further analysis of the literature and secondary data analysis. In reviewing the literature, the authors followed a the food system framework presented in Figure 2. The main domains for the research priorities are in line with the main components of this framework: Food Value Chains (Food Supply), Food environment, Consumer behavior, Drivers, and Trade-offs and Synergies. While the first four domains come directly from the framework, the last domain was chosen for the growing public concern and its increasingly integral role in the food systems approach (Ingram, 2011; Global Panel on Agriculture and Food Systems for Nutrition, 2016). 20 co-authors were asked to contribute with their own knowledge and expertise according to the main components. Besides, non-systematic literature search was conducted on Google scholar, Scopus and Google to identify additional sources. Peer-reviewed papers were mostly used to conceptualize and theorize, while various sources of gray paper were complemented to describe specific Viet Nam contexts, which are not always available in higher quality peerreviewed literature. Statistics for the country were collected from international reports and database such as by the World Bank and UNICEF, and national statistics from relevant agencies such as the National Institute of Nutrition and General Statistics Office. These statistics were used in particular to illustrate the nutrition transition of a typical LMIC like Viet Nam, for example changes in dietary patterns and food consumption trends.
The food system profile was created through this literature review and secondary data analysis, and research gaps were identified. The resulting food system profile has been published (Raneri et al., 2019). An example of research gap finding in the Drivers section is included in Supplementary Annex 2 of this paper. This food systems profile provides a solid evidence base for the next stage in the process.

This step took significant time, given the scope of the exercise and the large number of co-authors involved, as well as the data gaps. The connection with government partners in the research network, for example the General Statistics Office, was utilized to gain access to data and ministerial level documents that were not available to the public. Together, the coauthors developed a draft set of questions based on research gaps arising from the food system thematic areas corresponding with each section of the food systems profile.

As the final step of preparatory work, as an example for practical application of the research priorities, the researchers who initiated the exercise also classified priorities into themes that fit within the framework of their research program ${ }^{3}$.

\section{Determination of Priorities}

In identifying research priorities, two key criteria were used. First, Viet Nam's prioritized research questions should align with existing international and global agendas on food systems research. In particular, the research questions should directly contribute to building the evidence base to strengthen policies that emphasize "high quality diet," building more data and metrics for diet quality and food systems, better evaluation of policies and policy actions, climate accounting, and incentive structures (Global Panel on Agriculture and Food Systems for Nutrition, 2016; IFPRI, 2016). Secondly, national priorities as outlined in key policy documents were acknowledged and accounted for.

In assessment of the research priorities, an approach that combines consensus with metrics was used. The stakeholder workshop provided a consensus on the broad themes and key elements of the food systems. The Viet Nam food system profile, with the draft set of priority research questions, was circulated to a wide range of stakeholders with the $\mathrm{A} 4 \mathrm{NH}$ network for review prior to a validation stakeholder workshop that took place in June 2019. The criteria for priority setting were also mentioned in this document. Stakeholders were invited to provide their feedback externally to the planned workshop if they were unable to participate on the day of the workshop. Criteria for selecting the participants were the same as in the previous stakeholder workshop: coming from different sectors and different knowledge backgrounds. We then identified stakeholders to invite based on diversity of expertise, with the goal of ensuring equal representation from various sectors of the food system and areas of expertise. The workshop, however, only had about 20 participants besides the organizers (Table 2).

\footnotetext{
${ }^{3}$ The A4NH's implementation plan for the flagship Food Systems for Healthier diets involves three clusters of activities: Diagnosis and Foresight, Food Systems Innovation, and Upscaling and Anchoring of Food System Transformation.
} 
TABLE 2 | Participants in the second participatory workshop.

\begin{tabular}{llll}
\hline Domain for discussion & & Labor sector & \\
\hline Food supply & 4 & Researchers & 14 \\
Food environment & 4 & National government & 2 \\
Consumer behavior & 4 & Non-government organization & 3 \\
Diets, food safety, nutrition & 4 & Private sector & 3 \\
and health outcomes & & & \\
Drivers & 6 & International organization & 0 \\
\end{tabular}

Similarly with the first workshop, all the participants consented to the use of their discussions and opinions expressed during the workshops. Their names have been kept confidential in this paper. In this second stakeholder workshop, besides the draft list of research questions, which were grouped into themes, the participants brainstormed additional research questions or identified areas that required additional elaboration. Participants then broke up into parallel working groups, to further refine and add to the set of proposed questions, before proceeding to prioritization.

All the identified research questions (56) then went through a prioritization exercise, where stakeholders were asked to individually identify their top 15 priority research questions, across all thematic areas. A question got one point for every time it was selected by a respondent. We then added up the points for each question and ranked them. Supplementary Annex 2 shows the results of the full ranking and the prioritization of all questions within each thematic area.

Table 3 presents the list of prioritized research questions. While there was not a big difference in the number of priorities across the domain, food supply has the most number of questions (8), followed by synergies and trade-offs (7), nutrition and consumer behavior (6), drivers (5), and the food environment (4).

\section{Follow-Up to the Identification of Research Priorities}

To ensure transparency, the result of the food system profiling and priority setting exercise was disseminated via the $\mathrm{A} 4 \mathrm{NH}$ network and its partners, as well as published as an IFPRI discussion paper. As a follow up, this article was prepared to document the process in more detail, as well as assess how far the research priorities have been addressed to date. At the end of 2020, a quick survey of the stakeholders involved in the determination of priorities was carried out during a national year-end meeting to collect relevant research outputs. By the end of FSHD, a stock taking activity is planned to reflect on what the program has achieved in alignment with the identified research priorities.

\section{Research Follow-Ups}

At the time of writing, according to our knowledge, a quick check using Google Scholar citations of the working paper, and the survey of stakeholders at the end of 2020, a number of research outputs have aligned with the list of priority research questions. For example, the need for priority research question (RQ) number 9 "How are the interactions/dynamics between family, school and communities ensuring healthy diets for children" was responded by a study testing methods for healthier consumption in schools (Nguyen et al., 2020). Other examples include:

RQ6: New insights on the nexus of diet-related environmental impacts, food sourcing, and food choice motives along rural-urban population transect: Evidence from Vietnam (Trinh et al., 2021).

RQ7: Factors Associated with Food Safety Compliance among Street Food Vendors in Can Tho City, Vietnam: implications for intervention activity design and implementation (CISED, 2020).

RQ8: Tensions and coalitions: Trade agreements and the policy space for nutrition in Vietnam (Harris et al., forthcoming); Nutrition transition in Vietnam: changing food supply, food prices, household expenditure, diet and nutrition outcomes (Harris et al., 2020).

RQ12: Child overweight or obesity is associated with modifiable and geographic factors in Vietnam: implications for program design and targeting (Beal et al., 2020).

RQ15: Food policy and the unruliness of consumption: An intergenerational social practice approach to uncover transforming food consumption in modernizing Hanoi, Vietnam (Wertheim-Heck and Raneri, 2020).

RQ20: Nutrition landscape and climate in Vietnam: Identifying climate service entry points (Singh et al., 2020).

This list is not exhaustive, as it only registered studies that were reported by participants joining the workshop at the end of 2020 .

\section{Uptake of Research in Policy}

After the first planning workshop in 2016, the National Institute of Nutrition expressed the wish for deeper involvement with the network and an MOU was signed to facilitate A4NH's work on food systems research and the national institute. This marked the involvement of a national agency directly in charge of consulting health and nutrition-related issues for the Government in $\mathrm{A} 4 \mathrm{NH}$, which is expected to help disseminate the findings and policy recommendations to a higher level.

The A4NH Country Coordination and Engagement Unit (CCE) has employed the food framework mentioned in the paper to share and engage with Zero Hunger (ZH) National Action Plan in Vietnam. A4NH has involved for a year as a member in the technical working group of $\mathrm{ZH}$ to facilitate on nutrition sensitive work for the ZH implementation. Recently, the Ministry of Agriculture and Rural Development (MARD) has approved a training material for $\mathrm{ZH}$ staff on nutrition sensitive work in which the framework in the paper is credited in the training materials ${ }^{4}$ (Figure 5). In addition, food systems research products of A4NH were cited as references in the Member State Summit dialogues ${ }^{5,} 6$ in Vietnam ${ }^{7}$.

\footnotetext{
${ }^{4}$ https://blog.ciat.cgiar.org/update-food-systems-for-healthier-diets-a4nhcontributions-to-the-nutrition-sensitive-movement-in-vietnam-continue/ ${ }^{5}$ https://summitdialogues.org/dialogue/27771/

${ }^{6}$ https://summitdialogues.org/dialogue/35195/

${ }^{7}$ Alliance joins action on Food Systems dialogues in Vietnam|Alliance Bioversity
} International-CIAT (alliancebioversityciat.org). 
TABLE 3 | List of prioritized research questions.

What are the trade-offs and associations between agricultural production, health, environment (including agrobiodiversity and ecosystem services), and economic outcomes?

How to work with the private sector to promote healthy diets? What policies are necessary to regulate the private sector to promote health?

What is the potential of smallholder-oriented innovations in the food distribution systems?

How can we improve the management system/governance of food supply in Viet Nam?

Can healthier food choices lead to a healthier food supply?

What are the trade-offs between food safety, food waste, nutrition and environment?

What is the role of street food in Vietnamese diets and its nutritional outcomes?

What should Viet Nam do to promote healthy and diverse diets within the context of trade (liberalization, imports, foreign investments)?

How are the interactions/dynamics between family, school and communities ensuring healthy diets for children?

What are the costs and benefits for smallholders associated with the rise of different distribution and retail outlets?

What are some options to make modernization of the supply system more inclusive?

How do food policies interact with the determinants of obesity and NCDs?

What are the weak points along the supply chain regarding food loss management?

What interventions targeted at smallholders can improve food supply systems in Viet Nam?

Who are the winners and losers regarding environment, economic, health and nutrition outcomes of food-related opportunities brought about by urbanization?

To what extent, and how, are food system-related matters considered in urban planning?

How does the governance system (and its new laws, policies, etc.) affect the food system?

How does trust (e.g., food safety, traceability, etc.) affect consumption behavior?

What are the synergies and opportunities between the drivers of food system change?

How has climate change influenced the nutrition transition in Viet Nam?

How to harness the role of traditional beliefs and practices to improve diets (e.g., of ethnic community communities)?

How do new consumption trends/norms (e.g., vegetarianism, clean eating) affect the food system?

What are the effects of marketing campaign strategies from the private sector on diets and health?

What are storage knowledge gaps of farmers and traders?

What are the major nutrition-sensitive agriculture promotion strategies best suited for improving healthy diets, particularly among "vulnerable" groups incl. migrants and ethnic minorities?

What are child and adolescent initiated interventions that promote healthier diets at household, school and media levels?

How can food labeling initiatives have positive effects on the food system? Specifically, how can they improve consumer knowledge and empower consumers to make healthier food choices while also creating demand for healthier and safer food options from food companies?

How can emphasizing increasing consumer demand help shape or change production patterns to be more sustainable? What are the demand and supply incentives that are needed?

Have dietary consumption patterns followed agricultural production patterns or vice versa? How could the demand and supply relationship between production and consumption be better understood to shape healthier food systems, through shaping agriculture and nutrition policies?

What is the evidence of health benefits/harm of modernized diets compared to traditional ones?

Synergies and trade-offs

Food environment

2

Food supply

Food supply

Food supply

Synergies and trade-offs

Nutrition and consumer behavior

Synergies and trade-offs

Food environment

Food supply

Food supply

Food environment

Food supply

Food supply

Synergies and trade-offs

3 (tie)

3

3

3

7 (tie)

7

Drivers

Drivers

8 (tie)

8

8

9 (tie)

9

9

9

Nutrition and consumer behavior

Synergies and trade-offs

Drivers

Drivers

Drivers

Food environment

Food supply

Nutrition and consumer behavior

Nutrition and consumer behavior

Nutrition and consumer behavior

Synergies and trade-offs

Synergies and trade-offs

Nutrition and consumer behavior

16 (tie)

16

16

16

20 (tie)

20

20

20

20

20

aIndividual workshop participants could select a maximum of 15 priority questions from a list of 56 questions in total. We counted the number of times each question was listed. The most-listed question received priority order 1 , etc.

At the time of writing, Bioversity-CIAT alliance is preparing food systems priority-setting workshops at the local level for three urban-peri-urban-rural districts in Viet Nam. These workshops follow the framework of the national priority-setting exercise, with a stronger focus on actions (projects, programs and policies) taken at the local level that can come from research results. The food systems profiles for these three districts (Huynh, 2021) which were developed beforehand based on research, would be shared in these workshops.

\section{DISCUSSION}

This paper has described in detail the priority setting process for research on local food systems in Viet Nam. The 3-year process was inclusive, involving a large number of stakeholders from different sectors at different stages. Using a modern food system framework, the researchers and multisector stakeholders prepared a food systems profile for Viet Nam to take stock of the current evidence base, identify research gaps and propose 


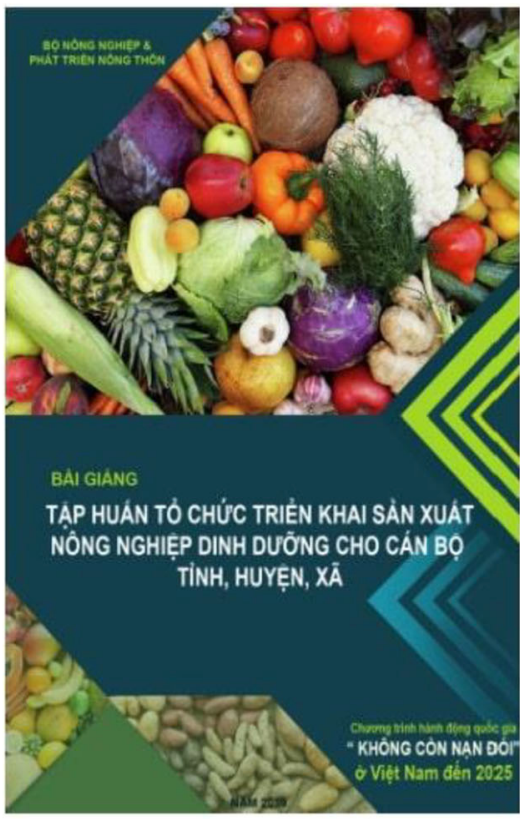

\section{Hệ thống lương thực thực phẩm, nông nghiệp dinh dưỡng và mối quan hệ với nạn đói}

a) Giảng viên giới thiệu tóm tắt về khái niệm hệ thống lương thực thực phẩm

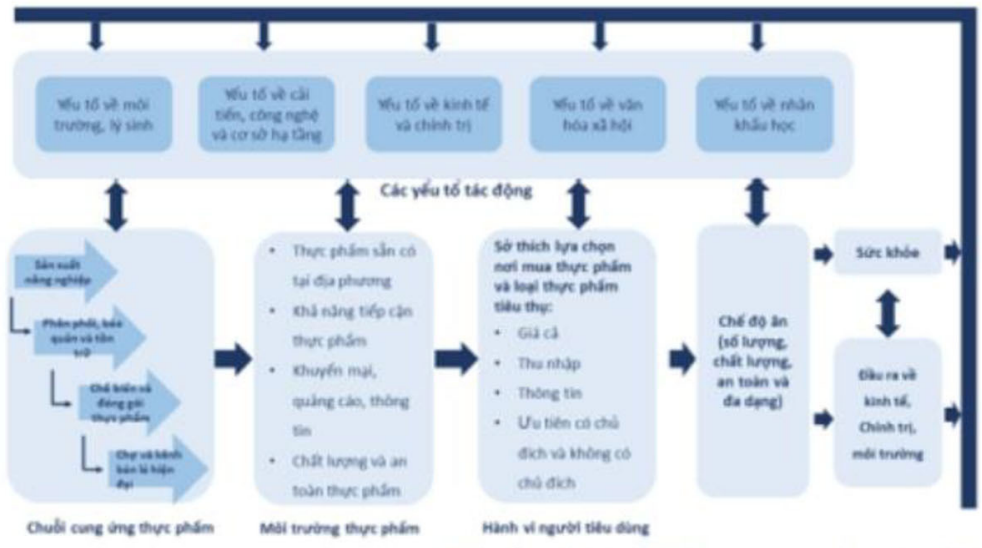

Nguồn: Jessica E. Raneri và cộng sụ. 2019

FIGURE 5 | Use of food systems framework in MARD training material for Zero Hunger

priorities for research. The final list of research priorities was developed based on aggregation of individual stakeholders' rankings. Initial research actions have been taken up based on the list of research priorities, although not all research questions have been tackled. Follow-up policy involvement has been initiated. The process achieved initial success in sensitizing local stakeholders about the food systems approach, which has been adopted by official documents approved by potential policy makers. Results of the process have been published and this article serves as another reporting product to enhance transparency.

Besides meeting the criteria of being evidence-based, inclusive and transparent as it set out to achieve, the process has also adopted several good practices from health and nutrition priority setting. To evaluate this, we used the checklist by Viergever et al. (2010), which identified the nine common themes of good research. Mador et al. (2016) conducted a similar evaluation.

First, to understand the context, during preparatory work, the exercise pooled a large amount of data and an extensive literature review, which was condensed into a food system profile for Viet Nam. This was the second study in the series by the initiating research program that seeks to identify research priorities at the national level, following the case of Ethiopia (Gebru et al., 2018), filling an important gap in priority setting for food systems. The expansion of this exercise, which is mostly practiced in health research, into food systems research will help to generate new lessons and key themes of good practice can start to emerge. As local culture can play a role in the priority setting process, a discussion of the taboos, beliefs and customs that influence consumption, as well as cultural drivers of food systems was also included in the review.
Second, the process made an effort to be inclusive, with all outputs circulated to workshop participants, shared with extended group of stakeholders for feedback, finalized and published as working papers after priorities have been set. While the exercise was put within the framework of $\mathrm{A} 4 \mathrm{NH}$ as a research initiative, the inclusion of ministerial representatives, government agencies and stakeholders outside the network gave opportunities to broaden the impact of the priority setting exercise. However, although the exercise involved various stakeholders, representatives in nutrition and health were overrepresented among policy stakeholders, and researchers still made up the majority, while the food systems approach requires a multidisciplinary joint effort. It was fortunate that this overrepresentation did not bias the list of research questions. In fact, the domains with the most prioritized research questions were food supply chains and synergies and trade-offs, which require a holistic lens. Apparently, to date we have not recorded any research outputs that tackled the top 5 research priorities, which are highly multidisciplinary in nature. The presence of stakeholders from more fields and expertise would have provided some practical suggestions on how to tackle the research questions. Future endeavors should seek to increase the limited presence of the private sector, which acts as the central driver the "missing middle" between production and consumption. This issue has also been observed in priority setting for health research (McGregor et al., 2014). Additionally, the underrepresentation of the public was also a drawback. There is a need to foster bottom-up approaches where priority setting exercises are led by citizens and affected members of the society instead of only academics (Sanders et al., 2004). Admittedly, attracting the public in academic-led discussions and workshops has always been 
challenging and not common (Tomlinson et al., 2011; McGregor et al., 2014). The next priority-setting exercises at the district level would enable more participation of the public.

Third, during information gathering, the process combined preliminary stakeholder consultation, extensive literature review and secondary data analysis to synthesize the existing evidence base. The literature review benefitted from knowledge and expertise of co-authors coming from different fields. In the food systems profile for Viet Nam, synergies and trade-offs in the local food system were also discussed (Raneri et al., 2019), making the review exercise more than a mere sum of the literature reviews on individual components of food systems. The information was timely shared with the stakeholders who were expected to spend time reading a very long profile paper to prepare for the validation and priority-setting workshop. A more concise version of this profile should have been available to facilitate this information-sharing mechanism.

Forth, the priority setting would benefit greatly from a more concrete planning for implementation. All the work so far on FSPR by Gebru et al. (2018), De Brauw et al. (2019), and Raneri et al. (2019) did not present or provide a follow-up to the priority exercises. It's important to not only focus on transparent research priority setting, but also provide followup and evaluation of such an initiative (Chalmers et al., 2014). Planning for implementation should already be done during the initial phase of a research priority setting exercise, especially where priorities are set by those not directly responsible for their implementation (Viergever et al., 2010). Our exercise produced an extensive and ambitious list of research questions, which could not be handled within the scope of a single research program. Besides, no one was designated to implement the priorities. It has also been argued that priority setting processes must have inbuilt mechanisms for publicizing results (Tomlinson et al., 2011). Although A4NH has had some initial studies and policy output that are part of the priorities, taking stock of all the research activities in Viet Nam that has addressed the priorities requires substantial effort. It is therefore recommended that the program, from the beginning, have a plan to reach out beyond its network to distribute the priorities and cover more research actions. A plan to monitor how the research priorities are addressed across sectors nationwide should be in place. In the plan, measures to assess the impacts of the research agenda should be clarified, as influence of research priority setting efforts may well go beyond citation of literature or tacit uptake in policies and practice (Sarli et al., 2010; Cruz Rivera et al., 2017).

Fifth, in terms of criteria, the process could benefit from further improvements. In assessing priorities, FSPR in Vietnam only had a minimal list of criteria, without quantifying these criteria. Criteria are used to focus discussion around research priorities and to ensure that important considerations are not overlooked. They also depend on identified values or principles of the exercise (Rudan et al., 2010). Identifying a set of criteria requires an inclusive process, which we did not have the resources to carry out. Therefore, instead of coming up with our own set of criteria, we gave more freedom to the stakeholders in determining what they found most important to them, thereby not imposing researcher-biased criteria on the stakeholders. As expected, participants did not raise any issue with the lack of clear-cut criteria. They simply used their personal expert judgement to select the priorities. Nevertheless, this lack of criteria has resulted in difficulties in assessing the research outputs. Indeed, we could not measure the research and policy outputs against any metrics to assess if they responded well to the issues in consideration. We could only map the research to the appropriate topics. In the follow-up priority setting exercises at the district level, with time resource allowed, more clear criteria would be available for respondents. FSPR can consider the criteria that have been used in health priority setting exercises, which can be at the population level (including burden, equity and efficacy and effectiveness), health systems level (workforce, political context and delivery), and research process and feasibility (knowledge generation, ethics, relevance, funding) (McGregor et al., 2014). Without a strict set of criteria, it is not surprising that some of the research questions (for example: "Can healthier food choices lead to a healthier food supply?") are abstract and overarching. Narrowing down the research scope to more "researchable" questions therefore was challenging and would hinder implementation.

Sixth, it had a clear method for deciding on priorities, which was a combination of consensus-based (during the workshop's participatory discussions) and metrics-based (pooling individual rankings in a survey) approach. In relation to the previous theme, an expanded list of criteria would facilitate the metrics-based approach better.

Seventh, the priority setting exercise did not make use of a comprehensive approach as no such approach that "provides structured, detailed, step-by-step guidance" from beginning to end is available for food systems research. Instead, this exercise adopted a "lighter" approach as per the analytical framework described in Proposed Approach and Methods for Food Systems Research Priority Setting section, and tried to incorporate lessons from other adjacent fields. With the discussion of characteristics of food systems analysis, this paper hopes to have contributed toward the development of such a comprehensive approach.

Eighth, the process maintained a high level of transparency. After each consultation workshop, a report was shared with the respondents, and the process was made known to all participants as well as funders. The key findings were shared in a working paper (Raneri et al., 2019), and this article is the latest effort to share the process with a larger audience.

Ninth, evaluation of the uptake of priority setting exercises is a challenging task. In this paper, we based the initial assessment of research results only on our own knowledge and a quick survey of stakeholders and provided simple measures of research-related impacts. Assessing research impact may also involve methods such as citation analysis research, meta-analysis, evaluation of interventions or technology, capacity building and academic collaborations, and data sharing (Cruz Rivera et al., 2017). Having a clear plan and specifying the expected impacts of the priority setting exercise would enable more meaningful follow-ups. 


\section{CONCLUSION AND POLICY IMPLICATIONS}

In conclusion, setting priorities for food system research is an involving activity, requiring extensive preparation work, high commitment from multidisciplinary stakeholders and a robust mechanism for planning, monitoring and evaluation. Building on the experiences of priority setting exercises in health and nutrition, the approach must also take into account the characteristics and challenges of food systems research and analysis. Nevertheless, the process and lessons learnt we described in this paper could serve as useful starting points for future similar endeavors. It would be useful to draw up a comprehensive approach as a step-by-step manual for facilitators of a national priority setting process.

The results from the priority setting research exercise can be used by multiple decision-makers. For funders, they serve as a foundation for future investments. For national and sub-national governments, they help drive research alignment with national policy and evidence needs and promote the relevance of conducted research. For intersectoral actors, they provide opportunities to reflect on their activities and future plans, with consequences for food systems outcomes. The process itself is a good way to sensitize local stakeholders on food systems approach, which would have substantial benefits in policy making to ensure that challenges are tackled from multiple perspectives and in a holistic way (Bhunnoo, 2019).

Amidst the concerns about increased burden of malnutrition on global health and the expected role of food systems in helping address these concerns, clear and transparent priorities for research and action at local levels are urgent. Food systems research can contribute to the Sustainable Development Goals (HLPE, 2017; Furman and Kaljonen, 2019; Brouwer et al., 2020). Nevertheless, priority setting exercises should not be conducted in isolation from related efforts, without stakeholders' integration into priority setting exercise from the beginning, and without more effective dissemination strategies (Hawwash et al., 2021). While researchers can initiate the priority setting process, governments, research funders and implementing stakeholders should actively support the effort, not only in setting priorities but also in dissemination and communication of the findings. As users of research outputs, decision makers can include their inputs, such as future plans, criteria and available resources. This user perspective is important to value the operational capacity of food systems analysis for mobilizing different key stakeholders to address common problems (Brouwer et al., 2020). Stronger uptake of the results, especially by funders, can help drive the research agenda, e.g., by facilitating knowledge transfer between different authors and research groups.

The importance of studying feedbacks and trade-offs to identify tensions between different components of the food system has been emphasized (Béné et al., 2019). During the food systems research priority setting process, the presence of a wide range of stakeholders provides a unique opportunity to enable dialogues about instruments to overcome the tradeoffs, such as how to organize interactions between multiple agents in food systems, and how to deal with conflicts between food systems objectives and outcomes. The process can also help uncover the bargaining relationships between different stakeholders and the feedback loops that may propel food system transformations, which has received insufficient attention in food systems reports (Brouwer et al., 2020). Although steering such processes is a challenge, it would be a worthy contribution to support meaningful applications of the food systems framework in practice.

\section{DATA AVAILABILITY STATEMENT}

The dataset presented in this study can be found at the following link https://docs.google.com/spreadsheets/d/ 1gJ7IvDfYjF2eLdDJYz6YQgR_DS7xL6QAzGuX27tf_P0/edit? usp=sharing.

\section{ETHICS STATEMENT}

Ethical review and approval was not required for the study on human participants in accordance with the local legislation and institutional requirements. The participants provided their written informed consent to participate in this study.

\section{AUTHOR CONTRIBUTIONS}

TN and JR prepared the first draft of the paper. JR led the data collection process and managed stakeholder involvement. TN supported data collection and stakeholder involvement. MB commented on the drafts and provided additional inputs in the final manuscript. TH supported the data collection process and provided additional inputs in the final manuscript. All authors contributed to the article and approved the submitted version.

\section{FUNDING}

This research was funded by and undertaken as part of the CGIAR Research Program on Agriculture for Nutrition and Health (A4NH) Research Flagship on Food Systems for Healthier Diets, and the Netherlands-CGIAR Research ProgrammeSenior Expert Programme (Grant number 17226).

\section{ACKNOWLEDGMENTS}

We would like to thank our colleagues at the Alliance of Bioversity International and CIAT (Hanoi office) who helped organize the participatory workshops. We also thank the national stakeholders who took part in the consultation process and identified key priority areas for research investments for Viet Nam's food system. 


\section{REFERENCES}

Battersby, J. (2020). "Data gaps and the politics of data" in Sustainable Food System Assessment: Lessons from Global Practice, eds. A. Blay-Palmer, D. Conare, K. Meter, A. Di Battista. London: C. Johnston Newgen Publishing UK.

Beal, T., Le, T. D., Trinh, H. T., Burra, D. D., Béné, C., Huynh, T. T. T., et al. (2020). Child Overweight or Obesity Is Associated with Modifiable and Geographic Factors in Vietnam: Implications for Program Design and Targeting. Nutrients 12:1286. doi: $10.3390 /$ nu12051286

Béné, C., Oosterveer, P., Lamotte, L., Brouwer, I. D., de Haan, S., Prager, S. D., et al. (2019). When food systems meet sustainability-current narratives and implications for actions. World Dev. 113, 116-130. doi: $10.1016 /$ j.worlddev.2018.08.011

Bhunnoo, R. (2019). The need for a food-systems approach to policy making. Lancet 393, 1097-1098. doi: 10.1016/S0140-6736(18)32754-5

Brouwer, I. D., McDermott, J., and Ruben, R. (2020). Food systems everywhere: improving relevance in practice. Glob. Food Sec. 26:100398. doi: 10.1016/j.gfs.2020.100398

Bryant, J., Sanson-Fisher, R., Walsh, J., and Stewart, J. (2014). Health research priority setting in selected high income countries: a narrative review of methods used and recommendations for future practice. Cost Eff. Resour. Alloc. 12, 1-11. doi: 10.1186/1478-7547-12-23

Bukachi, S. A., Onyango-Ouma, W., Siso, J. M., Nyamongo, I. K., Mutai, J. K., Hurtig, A. K., et al. (2014). Healthcare priority setting in Kenya: a gap analysis applying the accountability for reasonableness framework. Int. J. Health Plann. Manage. 29, 342-361. doi: 10.1002/hpm.2197

Burra, D. D., Thi Huong, T., Duong, T. T., Huynh, T., Haan, S., de Sánchez, A., et al. (2019). Vietnam Food Systems: Summary of Available Data and Vietnam Data Profile Annex. Hanoi, Viet Nam: CIAT: Advance Transitions Towards Sustainable Diets (EATS).

Chalmers, I., Bracken, M. B., Djulbegovic, B., Garattini, S., Grant, J., Gülmezoglu, A. M., et al. (2014). How to increase value and reduce waste when research priorities are set. Lancet 383, 156-165. doi: 10.1016/S0140-6736(13)62229-1

Chongtrakul, P., and Okello, D. (2000). A Manual for Research Priority Setting Using the ENHR Strategy. Genève: COHRED

CISED (2020). Factors Associated with Food Safety Compliance among Street Food Vendors in Can Tho City, Vietnam: Implications for Intervention Activity Design and Implementation. Can Tho, Viet Nam. Available online at: http://cids.org.vn/com_content/articles/hop-hoi-dong-tu-danh-gia-detai-cap-thanh-pho-nghien-cuu-danh-gia-hieu-qua-va-de- xuat-giai-phaphoan-thien-mo-hinh-an-toan-ve-sinh-thuc-pham-duong-pho-tai-thanhpho-can-tho/630.htm.

Cruz Rivera, S., Kyte, D. G., Aiyegbusi, O. L., Keeley, T. J., and Calvert, M. J. (2017). Assessing the impact of healthcare research: a systematic review of methodological frameworks. PLOS Med. 14:e1002370. doi: 10.1371/journal.pmed.1002370

De Brauw, A., Waid, J., Meisner, C. A., Akter, F., Ferdous Khan, B., Bhattacharjee, L., et al. (2019). Food Systems for Healthier Diets in Bangladesh Towards a Research Agenda. Washington: International Food Policy Research Institute. doi: $10.2499 / \mathrm{p} 15738$ coll2.133549

de Koning, S., de Haas, W., de Roo, N., Kraan, M., and Dijkshoorn-Dekker, M. (2021). Tools for Transitions: An Inventory of Approaches, Methods and Tools for Stakeholder Engagement in Developing Transition Pathways to Sustainable Food Systems. Ijmuiden: Wageningen Marine Research

Doolan-Noble, F., Mehta, P., Waters, D., and Baxter, G. D. (2019). Supporting ageing well research: findings from a research priority setting exercise. Aust. J. Ageing 38, 136-143. doi: 10.1111/ajag. 12615

Fanzo, J., Covic, N., Dobermann, A., Henson, S., Herrero, M., Pingali, P., et al. (2020). A research vision for food systems in the 2020s: defying the status quo. Glob. Food Sec. 26, 100397. doi: 10.1016/j.gfs.2020.100397

Finley, J. W., Dimick, D., Marshal, E., Nelson, G. C., Mein, J. R., and Gustafson, D. I. (2017). Nutritional sustainability: aligning priorities in nutrition and public health with agricultural production. Adv. Nutr. 8, 780-788. doi: 10.3945/an.116.013995

Furman, E., and Kaljonen, M. (2019). Sustainable Diets Enhance Progress on All Sustainable Development Goals. United Nations. Available online at: https://www.un.org/en/sustainable-diets-enhance-progress-all-sustainabledevelopment-goals (accessed August 4, 2021).
Gebru, M., Remans, R., Brouwer, I., Baye, K., Melesse, M. B., Covic, N., et al. (2018). Food Systems for Healthier Diets in Ethiopia: Toward a Research Agenda. IFPRI Discuss. Pap. 01720, 1-51.

Global Panel on Agriculture and Food Systems for Nutrition (2016). Food Systems and Diets: Facing the Challenges of the 21st Century. Available online at: http:// glopan.org/sites/default/files/ForesightReport.pdf (accessed August 21, 2021).

Ha, D. T., Feskens, E. J., Deurenberg, P., Mai, L. B., Khan, N. C., and Kok, F. J. (2011). Nationwide shifts in the double burden of overweight and underweight in Vietnamese adults in 2000 and 2005: two national nutrition surveys. BMC Public Health 11:62. doi: 10.1186/1471-2458-11-62

Haddad, L., Hawkes, C., Webb, P., Thomas, S., Beddington, J., Waage, J., et al. (2016). A new global research agenda for food. Nature 540, 30-32. doi: $10.1038 / 540030$ a

Harris, J., Nguyen, P. H., Tran, L. M., and Huynh, P. N. (2020). Nutrition transition in Vietnam: changing food supply, food prices, household expenditure, diet and nutrition outcomes. Food Secur. 12, 1141-1155. doi: 10.1007/s12571-020-01096-x

Hauck, K., Smith, P. C., and Goddard, M. (2015). The Economics of Priority Setting for Health Care: A Literature Review. Washington, DC: World Bank, 1-92.

Hawwash, D., Pinxten, W., Bonn, N. A., Verstraeten, R., Kolsteren, P., and Lachat, C. (2018). Perspective: consideration of values when setting priorities in nutrition research: guidance for transparency. Adv. Nutr. 9, 671-687. doi: 10.1093/advances/nmy039

Hawwash, D., Pinxten, W., Raneri, J. E., Kolsteren, P., and Lachat, C. (2021). Uptake and impact of priority setting exercises in nutrition research publications. Eur. J. Clin. Nutr. 75, 198-208. doi: 10.1038/s41430-020-00729-w

HLPE (2017). Nutrition and Food Systems: A Report by the High Level Panel of Experts on Food Security and Nutrition of the Committee on World Food Security. HLPE: Rome.

Hofmarcher-Holzhacker, M. M., Simon, J., and Perić, N. (2017). Priority Setting Methods in Health Information. Bridg. Heal. Tech. Rep. 04/2017 Recomm. Prior. setting methods an Eur. Res. Infrastruct. Consort. Heal. Inf. Res. Evidence-based Policy (HIREP-ERIC), HSandI Med. Univ. Vienna.

Huynh, T. T. T., Pham, T. M. H., Duong, T. T., Hernandez, R., Trinh, T. H., Nguyen, M. T., et al. (2021). Food systems profile along a rural - urban transect in North Viet Nam. Hanoi, Viet Nam: CIAT. Available online at: https://cgspace. cgiar.org/handle/10568/113417.

IFPRI (2016). Global Nutrition Report 2016: From Promise to Impact: Ending Malnutrition by 2030. Washington, DC: International Food Policy Research Institute (IFPRI)

Ingram, J. (2011). A food systems approach to researching food security and its interactions with global environmental change. Food Secur. 3, 417-431. doi: 10.1007/s12571-011-0149-9

Le Nguyen, B. K., Le Thi, H., Nguyen Do, V. A., Tran Thuy, N., Nguyen Huu, C., Thanh Do, T., et al. (2013). Double burden of undernutrition and overnutrition in Vietnam in 2011: results of the SEANUTS study in 5-11-year-old children. Br. J. Nutr. 110, S45-S56. doi: 10.1017/S00071145130 02080

Mador, R. L., Kornas, K., Simard, A., and Haroun, V. (2016). Using the Nine Common Themes of Good Practice checklist as a tool for evaluating the research priority setting process of a provincial research and program evaluation program. Heal. Res. Policy Syst. 14:22. doi: 10.1186/s12961-016-0092-5

McGregor, S., Henderson, K. J., and Kaldor, J. M. (2014). How are health research priorities set in low and middle income countries? A systematic review of published reports. PLOS ONE 9:e108787. doi: 10.1371/journal.pone. 0108787

Molini, V. (2006). Food Security in Vietnam During the 1990s: The Empirical Evidence. Oxford: Oxford University Press.

Montorzi, G., Haan, S., and De IJsselmuiden, C. (2010). Priority Setting for Research for Health: A Management Process for Countries. Geneva: The Council on Health Research for Development (COHRED). Available online at: http://www.cohred.org/downloads/Priority_Setting_COHRED_approach_ August_2010.pdf.

Nguyen, T., de Brauw, A., van den Berg, M., and Phuong Ha, D. T. (2020). Testing methods to increase consumption of healthy foods: evidence from a school-based field experiment in Viet Nam. Food Policy, 101:102047. doi: 10.2499/p15738coll2.133777 
Nguyen, T. T., and Hoang, M. V. (2018). Non-communicable diseases, food and nutrition in Vietnam from 1975 to 2015: The burden and national response. Asia Pac. J. Clin. Nutr. 27, 19-28. doi: 10.6133/apjen.032017.13

Raneri, J. E., Kennedy, G., Nguyen, T., Wertheim-Heck, S., Do, H., de Haan, S., et al. (2019). Determining Key Research Areas for Healthier Diets and Sustainable Food Systems in Viet Nam. Vietnam: IFRPI, 127. doi: 10.2499/p15738coll2.133433

Ruben, R., Verhagen, J., and Plaisier, C. (2018). The challenge of food systems research: what difference does it make? Sustainability 11, 1-14. doi: $10.3390 /$ su11010171

Rudan, I., Kapiriri, L., Tomlinson, M., Balliet, M., Cohen, B., and Chopra, M. (2010). Evidence-based priority setting for health care and research: tools to support policy in maternal, neonatal, and child health in Africa. PLoS Med. 7:e1000308. doi: 10.1371/journal.pmed.1000308

Rudan, I. (2016). Setting health research priorities using the CHNRI method: IV. Key conceptual advances. J. Glob. Health 6:010301. doi: 10.7189/jogh.06.010501

Sanders, D., Labonte, R., Baum, F., and Chopra, M. (2004). Making research matter: A civil society perspective on health research. Bull. World Health Organ. 82, 757-763. doi: 10.1590/S0042-96862004001000011

Sarli, C. C., Dubinsky, E. K., and Holmes, K. L. (2010). Beyond citation analysis: a model for assessment of research impact. J. Med. Libr. Assoc. 98, 17-23. doi: 10.3163/1536-5050.98.1.008

Singh, P., Huynh, T., and Downs, S. (2020). Nutrition Landscape and Climate in Vietnam: Identifying Climate Service Entry Points. Wageningen: CGIAR Research Program on Climate Change, Agriculture and Food Security (CCAFS)

Terry, R. F., Charles, E., Purdy, B., and Sanford, A. (2018). An analysis of research priority-setting at the World Health Organization-how mapping to a standard template allows for comparison between research priority-setting approaches. Heal. Res. Policy Syst. 16:116. doi: 10.1186/s12961-018-0391-0

Thornton, P. K., Whitbread, A., Baedeker, T., Cairns, J., Claessens, L., Baethgen, W., et al. (2018). A framework for priority-setting in climate smart agriculture research. Agric. Syst. 167, 161-175. doi: 10.1016/j.agsy.2018.09.009

Timotijevic, L., Khan, S. S., Raats, M., and Braun, S. (2019). Research priority setting in food and health domain: European stakeholder beliefs about legitimacy criteria and processes. Food Policy 83, 116-124. doi: 10.1016/j.foodpol.2018.12.005

Tomlinson, M., Chopra, M., Hoosain, N., and Rudan, I. (2011). A review of selected research priority setting processes at national level in low and middle income countries: towards fair and legitimate priority setting. Heal. Res. Policy Syst. 9, 1-7. doi: 10.1186/1478-4505-9-19

Tomlinson, M., Jordans, M., MacMillan, H., Betancourt, T., Hunt, X., and Mikton, C. (2017). Research priority setting for integrated early child development and violence prevention $(\mathrm{ECD}+)$ in low and middle income countries: an expert opinion exercise. Child Abus. Negl. 72, 131-139. doi: 10.1016/j.chiabu.2017.07.021

Tong, A., Synnot, A., Crowe, S., Hill, S., Matus, A., Scholes-Robertson, N., et al. (2019). Reporting guideline for priority setting of health research (REPRISE). BMC Med. Res. Methodol. 19, 1-11. doi: 10.1186/s12874-019-0 889-3

Trinh, H. T., Linderhof, V., Vuong, V. T., Esaryk, E. E., Heller, M., Dijkxhoorn, Y., et al. (2021). Diets, food choices and environmental impacts across an urban-rural interface in Northern Vietnam. Agriculture 11:137. doi: 10.3390/agriculture11020137

United Nations (2015). Transforming our world: the 2030 agenda for sustainable development. J. Public Health Policy 37, 13-31. doi: 10.1057/s41271-016-0 002-7

Viergever, R. F., Olifson, S., Ghaffar, A., and Terry, R. F. (2010). A checklist for health research priority setting: nine common themes of good practice. Heal. Res. Policy Syst. 8, 1-9. doi: 10.1186/1478-4505-8-36

Wertheim-Heck, S. C. O., and Raneri, J. E. (2020). Food policy and the unruliness of consumption: an intergenerational social practice approach to uncover transforming food consumption in modernizing Hanoi, Vietnam. Glob. Food Sec. 26:100418. doi: 10.1016/j.gfs.2020.100418

World Bank (2017). Vietnam Food Safety Risks Management: Challenges and Opportunities. Hanoi, Vietnam: World Bank.

Conflict of Interest: The authors declare that the research was conducted in the absence of any commercial or financial relationships that could be construed as a potential conflict of interest.

Publisher's Note: All claims expressed in this article are solely those of the authors and do not necessarily represent those of their affiliated organizations, or those of the publisher, the editors and the reviewers. Any product that may be evaluated in this article, or claim that may be made by its manufacturer, is not guaranteed or endorsed by the publisher.

Copyright (C) 2021 Nguyen, van den Berg, Raneri and Huynh. This is an open-access article distributed under the terms of the Creative Commons Attribution License (CC $B Y)$. The use, distribution or reproduction in other forums is permitted, provided the original author(s) and the copyright owner(s) are credited and that the original publication in this journal is cited, in accordance with accepted academic practice. No use, distribution or reproduction is permitted which does not comply with these terms. 